\title{
A pilot study on environmental and behavioral factors related to missed abortion
}

\author{
Xueyan Zhang $\cdot$ Jian Li $\cdot$ Yiqun Gu $\cdot$ \\ Yiming Zhao $\cdot$ Zhongxu Wang $\cdot$ Guang Jia
}

Received: 6 July 2010/ Accepted: 8 November 2010/Published online: 6 January 2011

(C) The Japanese Society for Hygiene 2011

\begin{abstract}
Objective The purpose of this study was to investigate the environmental and behavioral factors associated with the induction of missed abortion, with a particular focus on the relationship between job stress and missed abortion.

Methods This was a case-control study in which 552 women participated (267 cases, 285 controls). Job stress was measured using the Job Content Questionnaire 1.0 (JCQ1.0).

Results The case and control groups were significantly different for many factors, including age, physical exercise, exposure time to cell phone and computer, home refurbishment, ventilation, folic acid supplements, preference for fried food, reproductive knowledge, premarital health screening, parity, and supervisor support $(P<0.05)$. For
\end{abstract}

X. Zhang · G. Jia ( $₫)$

Department of Occupational and Environmental Health,

Peking University, Beijing 100191, China

e-mail: jiaguangjia@bjmu.edu.cn

X. Zhang $\cdot$ Z. Wang

National Institute of Occupational Health and Poison Control, Chinese Center for Disease Control and Prevention,

Beijing 100050, China

J. Li

Department of Safety Engineering,

University of Wuppertal, 42119 Wuppertal, Germany

Y. Gu

Haidian Maternal and Child Health Hospital,

Beijing 100080, China

Y. Zhao

The Third Hospital of Peking University,

Beijing 100083, China job stress, the univariate analysis revealed that there was no significant difference between cases and controls. Logistic analysis revealed that physical exercise (2-3 times per week or $>3$ times per week) [odds ratio (OR) $0.433,95 \%$ confidence interval (CI) $0.213-0.881$ or OR $0.268,95 \%$ CI $0.106-0.680$, respectively], ventilation (OR 0.415 , 95\% CI 0.251-0.685), folic acid supplements (OR 0.409, 95\% CI $0.265-0.633$ ), age (OR 1.102, 95\% CI 1.033-1.174), and supervisor support (OR 0.870, 95\% CI 0.768-0.986) were the significant factors contributing to the missed abortion $(P<0.05)$.

Conclusions Physical exercise, ventilation, folic acid supplements, and supervisor support were identified as protective factors for the prevention of missed abortion. Advanced age at pregnancy was a risk factor for missed abortion.

Keywords Missed abortion - Job stress -

Family stress - Risk factors

\section{Introduction}

Missed abortion is characterized by the arrest of embryonic or fetal development. The cervix is closed, and there is no or only slight bleeding. The prevalence of missed abortion is about $2 \%$ in singleton pregnancies at $10-14$ weeks of gestation [1]. In China, missed abortion is a widespread and serious clinical situation which not only damages the woman's health but also has great influence on population quality. In the past, studies on missed abortion have mainly focused on diagnosis and treatment when the embryo stopped growing. Recently, an increasing number of researchers are paying attention to the underlying causal factor of missed abortion. 
Job stress can be defined as "the harmful physical and emotional responses that occur when the requirements of the job do not match the capabilities, resources, or needs of the worker." The National Institute of Occupational Safety and Health (NIOSH) reported that more than one-third of all working individuals experienced high stress in one form or another [2]. In China, $20 \%$ of the working population have mental health problems [3]. It has been well accepted that women are more sensitive than men to the stresses of their job [4]. Job stress leads to poor health and even injury, such as cardiovascular diseases [5], musculoskeletal disorders [6], and mental illness [7], among others. The adverse influence of job stress on a woman's reproductive health includes infertility, menstrual disorders, lower conception rates, spontaneous abortion, and low birth weight [8]. In men, long-term stress does have an impact reproductive health. Also, the sperm of men who experience excessive grief or sorrow have a lower rate of linear motion and forward movement, temporarily reducing male reproductive ability [9]. To date, the relationship between job stress and missed abortion has not been clearly elucidated. The aim of our study was, therefore, to assess the potential factors related to the induction of missed abortion in the living and working environment, with a particular focus on the relationship between job stress and missed abortion.

\section{Materials and methods}

Cases and samples

The aim of this case-control study was to identify the differences between women who experienced a normal pregnancy (control) and those who experienced missed abortion (cases) while being treated at the HaiDian Maternal and Child Health Hospital, Beijing, China. This hospital delivers about one-third of all infants born in the greater Beijing area. The subjects were recruited during a 10-month period (7 March 2007 to 31 December 2007). A total of 600 questionnaires were distributed, and 570 were returned (response rate $95.0 \%$ ). Of these 570 respondents, 552 were initially included in the statistical analysis [267 cases and 285 normal (control) puerperas]. Respondents who were unemployed at recruitment $(n=66)$ were subsequently excluded, resulting in 486 subjects (236 cases and 250 controls) enrolled in the final job stress analysis. The principle of the declaration of Helsinki for using human subjects was followed. Ethical approval for this study was granted by the Committee of the Health Science Center, Peking University and local government authorities. Written informed consent was obtained from all participants prior to being enrollment.
Diagnosis of missed abortion

A diagnosis of missed abortion cases was made using clinical B ultrasound, which showed an empty gestational sac or an embryo/fetus without cardiac activity [10]. The assessment of missed abortion was performed by physicians who did not take part in the research and who were blind to the patient's job stress and levels of risk factors. The patients admitted to hospital with a normal delivery were defined as controls.

\section{Measurement}

A questionnaire-based interview was used to elicit details of job stress, family stress, environmental risk factors, life style, and medical history. A researcher carried out the interview face-to-face with each patient and her husband. The cases and controls were requested to complete the questionnaire on life style, medical history, environmental risk factors, family stress, and job stress. The interviewer would explain the questions should the patients not understand them clearly.

\section{Job stress}

Job stress was measured by the Chinese version of Job Content Questionnaire 1.0 (JCQ1.0). The questionnaire has been shown to perform acceptably and has been validated as a measurement tool of job stress in China [11]. The 22item JCQ1.0 includes three dimensions, namely, psychological job demands (5 items), decision latitude ( 9 items), and social support ( 8 items). All of the items refer to stress or stresslessness. The response to each item of the JCQ1.0 was scored on 4-point scale. For the responses to the stress aspects, a value of 1 indicates no stressful existence and a value of 4 indicates a high stressful existence. For the responses to stresslessness, a value of 4 indicates no stressful existence and a value of 1 indicates a very high stress level. In terms of the psychological demands of the work, the total score (5 items) increases with increasing levels of stress. In terms of decision latitude and social support, the scores of the items decrease with rising stress level. The relationship between the two scales of psychological job demands and decision latitude are then calculated to quantify the degree of disequilibrium between high demand and low control (the score of JCQ = psychological job demands/decision latitude). Stress level can be lightened by social support.

Family stress

The validated Chinese version of the Family Stress Scale $[12,13]$ was used to measure family stress. Each item of 
the Family Stress Scale was scored on 4-point scale $(1=$ very disagree, $2=$ disagree, $3=$ agree and $4=$ very agree), mirroring the respondents situation with respect to life events. The final score for family stress is based on the total score for each stressful event minus the total score for each positive event. A high score indicates high family stress.

Background information, environmental risk factors, life style, and medical history

In the context of this analysis, a women with a missed abortions was defined to have a family history. Marital status was categorized as unmarried, married, divorced, separated, and unmarried cohabitation. Education level was subdivided into post-high school, high school, college, university, Masters, and $\mathrm{PhD}$, respectively. Data on age, education level, smoking (no/yes; $<10$ cigarettes per day/ yes; $10-20$ cigarettes per day/yes; $>10$ cigarettes per day), drinking (no/yes), missed abortion family history (no/yes), marital status, parity $(0 / 1 / 2 / \geq 3$ times), and premarital health screening (no/yes) were collected in this questionnaire as background information. Physical exercise $(>3$ times per week/2-3 times per week/once per week/never), smoke exposure $(\mathrm{no} /<2 \mathrm{~h}$ per day $/ 2-3 \mathrm{~h}$ per day $/>3 \mathrm{~h}$ per day), exposure to cell phone and computer ( $<4 \mathrm{~h}$ per day/ $4-6 \mathrm{~h}$ per day/ $>6 \mathrm{~h}$ per day), noise exposure (no/yes), whether the noise had been defined as boring or as an unwanted sound in the working and living environment, home refurbishment (no/yes), ventilation (seldom/always), pet raising (no/yes), folic acid supplements (no/yes), preference for fried food (no/yes), and a knowledge of reproduction (always/seldom/never) were investigated as the environmental and behavioral factors by the questionnaire.

\section{Statistical analysis}

All analyses were performed using SPSS ver. 11.5 (SPSS, Chicago, IL). The Pearson chi-square test, Student's $t$ test and logistic regression analysis were used to compare associations between missed abortion and all of the potential factors, including background information, environmental and behavioral factors, job stress, and family stress. Odds ratios (OR) and $95 \%$ confidence intervals (CI) were used to examine the association between potential factors and missed abortion.

\section{Results}

The final sample size comprised 552 women (267 cases, 285 controls). Of the cases, the missed abortion occurred a mean of $9.3 \pm 2.8$ (standard deviation, SD) weeks after
Table 1 Background information on study cohort

\begin{tabular}{|c|c|c|c|}
\hline Characteristic & $\begin{array}{l}\text { Missed } \\
\text { abortion }\end{array}$ & $\begin{array}{l}\text { No missed } \\
\text { abortion }\end{array}$ & $P$ \\
\hline Age (years) & $30.0 \pm 4.0$ & $29.2 \pm 3.4$ & 0.035 \\
\hline Education $(n)$ & & & 0.335 \\
\hline Post-high school student & $27(9.9 \%)$ & $16(5.6 \%)$ & \\
\hline High school student & $30(11.2 \%)$ & $43(15.1 \%)$ & \\
\hline College student & $62(21.6 \%)$ & $66(23.2 \%)$ & \\
\hline Bachelor & $101(38.8 \%)$ & $104(36.5 \%)$ & \\
\hline Master & $36(14.2 \%)$ & $45(15.8 \%)$ & \\
\hline $\mathrm{PhD}$ & $11(4.3 \%)$ & $11(3.9 \%)$ & \\
\hline Smoking $(n)$ & & & 1.000 \\
\hline No & $265(99.3 \%)$ & $282(98.9 \%)$ & \\
\hline$<10 /$ day & $2(0.7 \%)$ & $3(1.1 \%)$ & \\
\hline 10-20/day & 0 & 0 & \\
\hline$>20 /$ day & 0 & 0 & \\
\hline Drinking $(n)$ & & & 0.297 \\
\hline No & $245(91.8 \%)$ & $268(94.0 \%)$ & \\
\hline Yes & $22(8.2 \%)$ & $17(6.0 \%)$ & \\
\hline Family history $(n)$ & & & 0.251 \\
\hline No & $257(96.3 \%)$ & $279(97.9 \%)$ & \\
\hline Yes & $10(3.7 \%)$ & $6(2.1 \%)$ & \\
\hline Marital status (n) & & & 0.113 \\
\hline Unmarried & $3(1.1 \%)$ & 0 & \\
\hline Married & $264(98.9 \%)$ & $283(99.3 \%)$ & \\
\hline Divorced & 0 & $1(0.4 \%)$ & \\
\hline Separated & 0 & 0 & \\
\hline Unmarried cohabitation & 0 & $1(0.4 \%)$ & \\
\hline Parity $(n)$ & & & 0.000 \\
\hline 0 & $158(66.7 \%)$ & $185(70.9 \%)$ & \\
\hline 1 & $29(12.2 \%)$ & $68(26.1 \%)$ & \\
\hline 2 & $29(12.2 \%)$ & $7(2.7 \%)$ & \\
\hline$\geq 3$ & $21(8.9 \%)$ & $1(0.4 \%)$ & \\
\hline Premarital health screening $(n)$ & & & 0.040 \\
\hline No & $152(57.4 \%)$ & $138(48.6 \%)$ & \\
\hline Yes & $113(42.6 \%)$ & $146(51.4 \%)$ & \\
\hline
\end{tabular}

Values are given as the mean \pm standard deviation (SD) for continuous variables and as the number $(n)$ with the within-column percentage given in parenthesis for numeration data. Numbers may not total $100 \%$ due to missing data and rounding-off

$P$ value is for $t$ test (continuous variables) or chi-square (numeration datas)

menelipsis. Differences in background information provided by the cases and controls are shown in Table 1 . There were no differences in smoking, drinking, family history, marital status, and education level between cases and controls. Cases were more likely to be older, to have higher parities, and less likely to accept the premarital health screenings $(P<0.05)$.

Table 2 shows the associations between job stress, environmental and behavioral factors, and missed abortion. 
Table 2 Job stress, environmental, and behavioral factor analysis

\begin{tabular}{|c|c|c|c|}
\hline Characteristic & $\begin{array}{l}\text { Missed } \\
\text { abortion }\end{array}$ & $\begin{array}{l}\text { No missed } \\
\text { abortion }\end{array}$ & $P$ \\
\hline Physical excise (time/week) & & & 0.000 \\
\hline$>3$ & $12(4.5 \%)$ & $28(9.8 \%)$ & \\
\hline $2-3$ & $17(6.4 \%)$ & $39(13.7 \%)$ & \\
\hline 1 & $58(21.7 \%)$ & $68(23.9 \%)$ & \\
\hline Never & $180(67.4 \%)$ & $150(52.6 \%)$ & \\
\hline Passive smoke (h/day) & & & 0.062 \\
\hline No & $162(60.7 \%)$ & $157(55.1 \%)$ & \\
\hline$<2$ & $79(29.6 \%)$ & $108(37.9 \%)$ & \\
\hline $2-3$ & $12(4.5 \%)$ & $14(4.9 \%)$ & \\
\hline$>3$ & $14(5.2 \%)$ & $6(2.1 \%)$ & \\
\hline $\begin{array}{l}\text { Exposure to cell phone and } \\
\text { computer (h/day) }\end{array}$ & & & 0.044 \\
\hline$<4$ & $46(17.2 \%)$ & $72(25.3 \%)$ & \\
\hline $4-6$ & $62(23.2 \%)$ & $69(24.2 \%)$ & \\
\hline$>6$ & $159(59.6 \%)$ & $144(50.5 \%)$ & \\
\hline Noise exposure & & & 0.198 \\
\hline No & $163(61.0 \%)$ & $189(66.3 \%)$ & \\
\hline Yes & $104(39.0 \%)$ & $96(33.7 \%)$ & \\
\hline $\begin{array}{l}\text { Refurbishing home } 3 \text { months } \\
\text { before and during pregnancy }\end{array}$ & & & 0.024 \\
\hline No & $154(57.7 \%)$ & $191(67.0 \%)$ & \\
\hline Yes & $113(42.3 \%)$ & $94(33.0 \%)$ & \\
\hline Ventilation & & & 0.000 \\
\hline Seldom & $90(33.7 \%)$ & $47(16.5 \%)$ & \\
\hline Always & $177(66.3 \%)$ & $238(83.5 \%)$ & \\
\hline Pet raising & & & 0.851 \\
\hline No & $231(86.5 \%)$ & $245(86.0 \%)$ & \\
\hline Yes & $36(13.5 \%)$ & $40(14.0 \%)$ & \\
\hline Folic acid supplements & & & 0.000 \\
\hline No & $160(61.3 \%)$ & $122(42.8 \%)$ & \\
\hline Yes & $101(38.7 \%)$ & $163(57.2 \%)$ & \\
\hline Favoring fried food & & & 0.013 \\
\hline No & $158(61.0 \%)$ & $205(71.9 \%)$ & \\
\hline Yes & $101(39.0 \%)$ & $80(28.1 \%)$ & \\
\hline Have reproductive knowledge & & & 0.000 \\
\hline Always & $107(40.4 \%)$ & $168(58.9 \%)$ & \\
\hline Seldom & $147(55.5 \%)$ & $106(37.2 \%)$ & \\
\hline Never & $11(4.2 \%)$ & $11(3.9 \%)$ & \\
\hline Family stress & $-1.25 \pm 3.2$ & $-1.76 \pm 3.2$ & 0.062 \\
\hline Job stress & $0.51 \pm 0.1$ & $0.50 \pm 0.1$ & 0.202 \\
\hline
\end{tabular}

Values are given as the mean \pm standard deviation (SD) for continuous variables and as the number $(n)$ with the within-column percentage given in parenthesis for numeration data. Numbers may not total $100 \%$ due to missing data and rounding-off

$P$ value is for $t$ test (continuous variables) or chi-square (numeration datas)
For the job stress analysis only, the actual numbers of cases and controls included were 236 and 250, respectively. There were no differences between the two groups in terms of passive smoke, noise exposure, pet raising, family stress, and job stress. Cases were more likely to use the computer and cell phone $>6 \mathrm{~h}$ per day, to refurbish their homes within 3 months before to being pregnant or during pregnancy, and to prefer fried food $(P<0.05)$. Controls were more likely to participate in physical excise, ventilate their rooms, use folic acid supplements prior to conception and during pregnancy, and to obtain reproductive knowledge $(P<0.05)$.

Information on the dimensions of job stress, as evaluated by JCQ, were compared between case and control groups, and the data are presented in Table 3. Among the respondents to the JCQ, the score of supervisor support was lower for the cases than for the controls $(P<0.05)$. Cases were more likely to get less supervisor support. There were no significant difference for the other dimensions between cases and controls.

Table 4 shows the logistic regression model that was used to estimate the relationship between potential factors and missed abortion. In the initial analysis, all of the observed factors were entered in the model. Thereafter, age, physical exercise, ventilation, folic acid supplements, and supervisor support were entered in the model $(P<0.05)$. Age significantly increased the risk of missed abortion (OR 1.107, 95\% CI 1.037-1.181). Compared to never exercising, exercise activity three times per week decreased the possibility of missed abortion (OR 0.279, 95\% CI 0.108-0.716). Ventilation was associated with a reduced missed abortion risk (OR 0.430, 95\% CI 0.258-0.718). Folic acid supplementation was a protective factor, reducing the risk of missed abortion (OR 0.399, 95\% CI 0.254-0.626). High supervisor support was significantly associated with a decreased missed abortion risk (OR 0.859, 95\% CI 0.757-0.975).

\section{Discussion}

Missed abortion has become an important public health problem that directly affects the sustained development of the Chinese population. In China, the incidence of missed abortion is about $13.4 \%$ [14]. There are many causal factors, both from the environment and/or the individual, resulting in a complex causal relationship. In our casecontrol study, environmental and individual factors, with a special focus on job stress, were investigated. The findings provide the basis for further cohort studies.

Job stress has become a new occupational adverse factor in China, affecting female reproduction health in the form 
Table 3 Job stress analysis between two groups

\begin{tabular}{llll}
\hline Factors related to job stress & Missed abortion $(n=236)$ & No missed abortion $(n=250)$ & $P$ \\
\hline Psychological job demands & $31.6 \pm 4.6$ & $31.4 \pm 4.0$ & 0.578 \\
Skill decision & $31.2 \pm 4.4$ & $31.6 \pm 3.9$ & 0.274 \\
Decision authority & $32.7 \pm 5.6$ & $33.2 \pm 5.2$ & 0.389 \\
Coworker support & $11.5 \pm 1.5$ & $11.7 \pm 1.4$ & 0.125 \\
Supervisor support & $10.5 \pm 1.9$ & $10.9 \pm 1.8$ & 0.030 \\
\hline
\end{tabular}

Values are given as the mean \pm SD for continuous variables

$P$ value is for $t$ test (continuous variables)

Table 4 Model of logistic regression of potential factors on missed abortion

\begin{tabular}{llll}
\hline Variable & Odds ratio & $\begin{array}{l}\text { 95\% confidence } \\
\text { interval }\end{array}$ & $P$ \\
\hline Age & 1.102 & $1.033-1.174$ & 0.003 \\
Excise (week) & & & \\
$>3$ & 0.268 & $0.106-0.680$ & 0.006 \\
$2-3$ & 0.433 & $0.213-0.881$ & 0.021 \\
1 & 0.833 & $0.496-1.401$ & 0.491 \\
Never & 1 & - & - \\
Ventilation & 0.415 & $0.251-0.685$ & 0.001 \\
Folic acid supplements & 0.409 & $0.265-0.633$ & 0.000 \\
Supervisor support & 0.870 & $0.768-0.986$ & 0.029 \\
\hline
\end{tabular}

$P$ value is for $t$ test (continuous variables)

of algomenorrhea, low birth weight [15], miscarriage [16], and preeclampsia [17]. The positive association between job stress and missed abortion is an important highlight of our study. Although the score for job stress was not significantly different between case and control groups based on the JCQ scores, the logistic regression analysis revealed that supervisor support was a protective factor that reduced the missed abortion risk. In contrast, there was no significant association between each of the other four subdimensions and missed abortion risk at the $P=0.05$ level of significance. These results suggest that the missed abortion cases had less supervisor support than did the controls $(P=0.019)$.

In addition to job stress, the regression also revealed that various factors, including age, physical exercise, folic acid supplements, and ventilation, were associated with the missed abortion. In this case-control study, advanced age at pregnancy was a risk factor for missed abortion (OR 1.107, 95\% CI 1.037-1.181). The ovum ages and degenerates with increasing age; moreover, there is a positive relationship between age at pregnancy and chromosome aberration. An earlier study performed in China found that women aged $>33$ years were at high risk of missed abortion (OR 4.38) [18]. Another study also reported that the incidence of missed abortion increases at an age at pregnancy of $<19$ years or $>35$ years [19]. Importantly, physical exercise could decrease the onset risk of missed abortion. It has been noted that regular physical exercise is beneficial for relieving anxiety and stress [20] and improving physical fitness among pregnant women [21]. In our case-control study, ventilation was a protective factor to missed abortion. Regular ventilation occurred in $83.5 \%$ of the control families and only in $66.3 \%$ of the case families. In this study, the use of folic acid supplements before or during pregnancy decreased the odds of missed abortion (OR $0.399,95 \%$ CI $0.254-0.626$ ): $57.2 \%$ of women without missed abortion took folic acid supplements before or during pregnancy in comparison to only $38.7 \%$ of missed abortion cases. Folic acid supplements have been shown to be able to prevent placental abruption [22]. A survey in Shanxi province of China demonstrated that the rate of using folic acid among Chinese women was still low-only $10.2 \%$ [23].

In summary, the results of this study show that a high level of supervisor support, exercise several times weekly, ventilation, and folic acid supplements were associated with a decreased risk of missed abortion. Further studies with larger sample sizes and improved cohort study design will be needed to confirm these potential factors and their dose-response relations of missed abortion.

\section{References}

1. Sebire NJ, Thornton S, Hughes K, Snijders RJ, Nicolaides KH. The prevalence and consequences of missed abortion in twin pregnancies at 10 to 14 weeks of gestation. Br J Obstet Gynaecol. 1997;07:847-8.

2. National Institute of Occupational Safety and Health (NIOSH). Working with stress. Publication number 2003-114d. 2002. Available at: http://www.cdc.gov/niosh/docs/video/stress1.html. Accessed 16 April 2008.

3. Fan XY. Epidemiological study of job stress (to be continued). Occup Health Emerg Rescue. 2004;01:53.

4. de Smet P, Sans S, Dramaix M, Boulenguez C, de Backer G, Ferrario M, et al. Gender and regional differences in perceived job stress across Europe. Eur J Public Health. 2005;05:536-45. 
5. Dimsdale JE. Psychological stress and cardiovascular disease. J Am Coll Cardiol. 2008;13:1237-46.

6. Chen JC, Chang WR, Chang W, Christiani D. Occupational factors associated with low back pain in urban taxi drivers. Occup Med (Lond). 2005;07:535-40.

7. Eum KD, Li J, Lee HE, Kim SS, Paek D, Siegrist J, et al. Psychometric properties of the Korean version of the effort-reward imbalance questionnaire: a study in a petrochemical company. Int Arch Occup Environ Health. 2007;08:653-61.

8. Brandt LP, Nielsen CV. Job stress and adverse outcome of pregnancy: a causal link or recall bias. Am J Epidemiol. 1992;03:302-11.

9. Wu JQ, Gao ES, Yang QY, Tao JG, Liang CL, Xu X. The investigation on working and other lifestyles influencing semen quality of Chinese young men. Chin J Fam Plan. 2004;06:346-9.

10. Gemzell-Danielsson K, Ho PC, Ponce Gómez, de León R, Weeks A, Winikoff B. Misoprostol to treat missed abortion in the first trimester. Int J Gynaecol Obstet. 2007;02:182-5.

11. Li J, Yang W, Liu P, Xu Z, Cho SI. Psychometric evaluation of the Chinese (Mainland) version of job content questionnaire: a study in university hospitals. Ind Health. 2004;02:260-7.

12. Karasz A, Outllette SC. Role strain and psychological well-being in women with systemic lupus erythematosus. Women Health. 1995;03:41-57.

13. Xu L, Siegrist J, Cao W, Li L, Tomlinson B, Chan J. Measuring job stress and family stress in Chinese working women: a validation study focusing on blood pressure and psychosomatic symptoms. Women Health. 2004;02:31-46.
14. Liu FR. Discussion of health care in early pregnancy. Matern Child Health Care China. 2000;02:100-1.

15. Rogal SS, Poschman K, Belanger K, Howell HB, Smith MV, Medina $J$, et al. Effects of posttraumatic stress disorder on pregnancy outcomes. J Affect Disord. 2007;01-03:137-43.

16. Silvana S, Marra C, Irene FT. Ageing in nursing: a ten year follow up study. Int Congr Ser. 2005;1280:124-9.

17. Klonoff-Cohen HS, Cross JL, Pieper CF. Job stress and preeclampsia. Epidemiology. 1996;03:245-9.

18. Feng ZH. Analysis about reason of repeated missed abortion. J Chin Physician. 2005;10:1382-3.

19. McFadyen IR. Missed abortion, and later spontaneous abortion, in pregnancies clinically normal at 7-12 wk. Eur J Obstet Gynecol Reprod Biol. 1985;06:381-4.

20. Siddiqui NI, Nessa A, Hossain MA. Regular physical exercise: way to healthy life. Mymensingh Med J. 2010;01:154-8.

21. Koltyn KF, Schultes SS. Psychological effects of an aerobic exercise session and a rest session following pregnancy. J Sports Med Phys Fitness. 1997;04:287-91.

22. Nilsen RM, Vollset SE, Rasmussen SA, Ueland PM, Daltveit AK. Folic acid and multivitamin supplement use and risk of placental abruption: a population-based registry study. Am J Epidemiol. 2008;07:867-74.

23. Li Z, Ren A, Zhang L, Liu J, Li Z. Periconceptional use of folic acid in Shanxi Province of northern China. Public Health Nutr. 2007;05:471-6. 